\title{
Design errors and performance defects as causes of the risk for a collapse of the ceiling of the concert hall
}

\author{
Ryszard Chmielewski ${ }^{1}$, Leopold Kruszka ${ }^{2}$ \\ Faculty of Civil Engineering and Geodesy, Military University of Technology, Warsaw, Poland \\ E-mail: ${ }^{2}$ leopold.kruszka@wat.edu.pl (correspondingauthor)
}

\begin{abstract}
The issue presented concerns the proper assessment of a ceiling underneath a modernised concert hall in a historic building as a case study. The reason for a reconstruction was to replace a wood block floor with stone slab floor made of marble. Shortly after the construction works, cracks which appeared, made the floor unsuitable for further use. In order to determine the cause of the damage, a detailed analysis of a state of the construction was performed within the technical diagnostics. The first element that was inspected was the way the cracks were distributed. This layout was typical for overloading of ceiling. It was assumed that the thickness of the concrete overlay of the Ackerman floor was $9 \mathrm{~cm}$. In order to verify the actual layout of the floor layers, five different opencast works were taken from the top level of the floor cavity blocks. The actual layout of the uncovered parts differed from both the assumptions that were made and the new design. The arrangement of the floor layers that differed from the design documents, caused the overloading of the supporting structure of the Ackerman floor. Additionally, an incorrect design assumption has overlapped.
\end{abstract}

Keywords: repair of ceiling structure, renovation of historic building.

\section{Introduction}

Scratches and cracks are a fairly common issue that occurs during renovation or redevelopment of historic buildings. This kind of damage in historic masonry constructions usually appears due to errors in establishing properties of embedded building materials or construction geometry (Kruszka, 2018). This article presents the methodology of examining root causes of the risk of construction failure that developed in a renovated concert hall (Chmielewski \& Kruszka, 2005-2017).

Renovations of historic buildings require a set of design solutions that will ensure that repair work carried out will bring expected results. The most common projects given to heritage preservationists in Poland require securing the original building blocks and the overall look of modernised object (Chmielewski \& Kruszka, 2015). Appearance of scratches and cracks on elements of load bearing masonry construction is a common problem. This sort of constructional damage on bearing walls may be caused by uneven settlement of the building object, local exceeding of allowable strains (e.g. increase in operational load), loss of longitudinal stability and rigidity of walls, also due to thermal stress caused by temperature change. Stone partition walls are quite often removed or new floor layers are added during the execution of construction work. That often causes significant constructional damage to a supporting structure and in extreme cases, to construction failure. A building inspector who compiles assessments and evaluations of technical damage to a masonry construction in some cases as a solution recommends only surface reinforcement of damaged walls (Chmielewski, Kruszka, \& Lalka, 2016). The issue of a significant change in the distribution of loads in reconstructed buildings with classic construction without ring beams is a complex subject and in certain cases, the above solution might be insufficient in order to ensure the safety of a supporting construction or secure exploitation of a building.

This case study presents a diagnostics and analysis carried out on a construction of an intermediate floor that got ballasted with additional floor layers. The case described in this paper presents a methodology of evaluating reasons behind the identified faults and presents an effective way of removing the risk of construction damage. There are different methods that are used to strengthen a construction of a building and it is usually the use of light ultra-durable materials which was described in many studies (Kumar, 2016; Brühwiler \& Denarié, 2013; Radziszewska-Zielina, Kania, \& Śladowski, 2018). These are correct solutions but in the presented case it was decided to relieve the building structure. Reasons behind it were based on a cost of this sort of solution as well as due to constructional reasons. 
Additionally, the load increase of incorrectly made floor layers could have caused local overload of other structural components. It should be noted that the cracked stone floor slabs had to be removed regardless of a taken approach.

\section{Description of the concert hall floor state}

Stone-slab floor - the last floor layer in the concert hall was replaced as a part of the reconstruction that was done in 2008. As a result of construction work the arrangement of existing floor layers at the time (according to the project documents, Studio AZR, 2007) consisted of:

-Ackerman floor: $27 \mathrm{~cm}$,

$-2 \times$ fiberboard,

- screed: $4 \mathrm{~cm}$,

-wooden floor: $2.2 \mathrm{~cm}$,

And designed floor layers with stone-slab floor:

-Ackerman floor: $27 \mathrm{~cm}$ (as above),

- stabilised sand: $7 \mathrm{~cm}$,

- stone-slab floor: $2 \mathrm{~cm}$.

In order to verify the actual state of the layout of the floor layers, five different opencast works from the top level of the floor cavity blocks of Ackerman floor were made - see Figure 1.
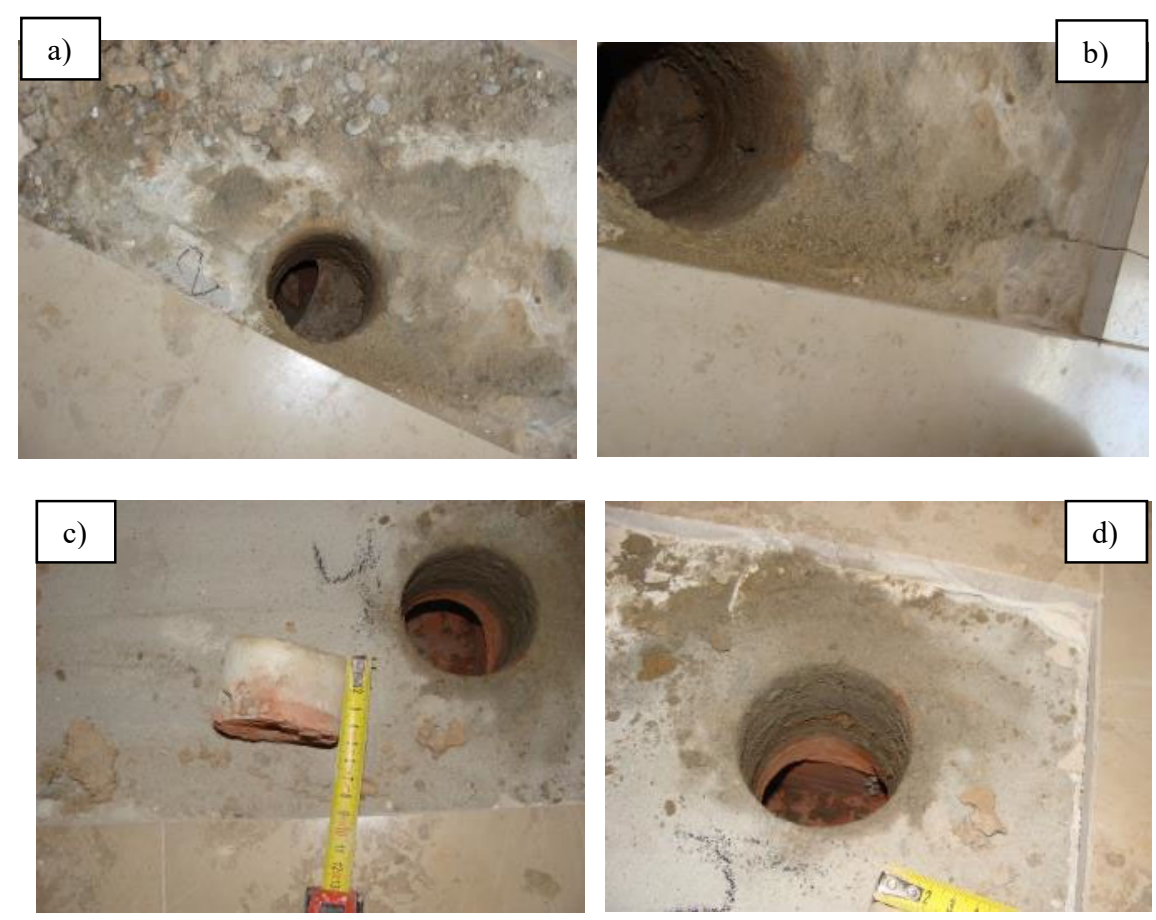

Figure 1. Examples of opencast works from floor layers: a, b) no. 2, c, d) no. 4

Basing on the opencast works it was established that assumptions of the statistical formulas attached to the design documentation of the building redevelopment were incorrect. The thickness of the Ackerman floor concrete overlay is about $3 \mathrm{~cm}$ (see Figure 1c) while in the design calculations (Studio AZR, 2007) and technical expertise preceding the renovation (Studio AZR, 1998), a thickness of $9 \mathrm{~cm}$ was assumed. That caused a significant increase of the value of the lever arm of internal forces and thereby the load bearing capacity of the floor was overstated. The lever arm of internal forces for bending assumed under design calculations is $23.0 \mathrm{~cm}$ and the actual one - calculated for the analyzed opencast works is $18.5 \mathrm{~cm}$ which means a reduction of the lever arm by over $24 \%$. Additionally, the floor layers that had been made are not consistent with the design documentation. The design specification (Studio AZR, 2007) assumed $7 \mathrm{~cm}$ of stabilised sand with a characteristic load of $1.33 \mathrm{kN} / \mathrm{m}^{2}$ when in reality there is an average of $6.5 \mathrm{~cm}$ of concrete screed and $1.0 \mathrm{~cm}$ of adhesive which amounts to a characteristic load of $1.74 \mathrm{kN} / \mathrm{m}^{2}$.

The actual cross-section of the floor layers established on the grounds of local opencast works presents as follows:

- cement and lime plaster: $1.5 \mathrm{~cm}$,

-Ackerman floor: $21 \mathrm{~cm}$,

-screed (average): $4 \mathrm{~cm}$, 
- fiberboard and vapor barrier: $1.0 \mathrm{~cm}$,

- concrete screed: $6.5 \mathrm{~cm}$,

- adhesive mortar: $1.0 \mathrm{~cm}$,

- stone floor: $2.0 \mathrm{~cm}$

During the site inspection, the technical condition of the intermediate floor from the bottom of the construction was also assessed - Figure 2.
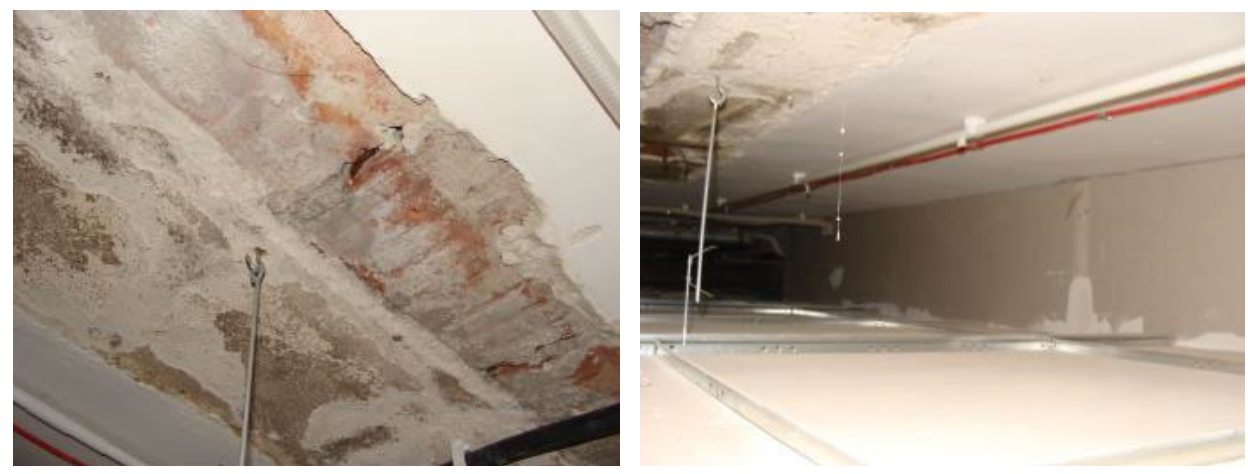

Figure 2. Views of the construction of Ackerman floor from the bottom

Looking at the bottom of the construction there were no signs of damage on the supporting structure. A ferromagnetic device was used to measure the thickness of the cover of reinforcing bars which is $2.0 \mathrm{~cm}$ and the diameter of the reinforcing bar of the floor rib was $10 \mathrm{~mm}$.

Based on the conducted research of floor layer opencast works and visual assessment of the damaged marble floor surface in the concert hall of "Dziekanka" historic building in Warsaw, it was ascertained that:

- cracks on the stone-slabs of the floor are consisted of the cracks of the layers of adhesive and base surface: the performance deffect,

- the layout of the floor layers is inconsistent with the design documentation which caused overload of the Ackerman ceiling load- bearing construction, including operational load (crowd of people) that was taken into account: the performance defects and design errors,

- the amount and the thickness of dilatation is insufficient: the performance defect,

- dilatations and construction joints of the base surface are inconsistent with the floor surface dilatations: the performance defect.

\section{Root cause analysis of observed irregularities}

The analysis of the technical documentation of the renovation, indicated a number of errors and inaccuracies. In the calculations in 1998, the designer estimated the load-bearing of the beam floor as $M_{R d}=2.84 \mathrm{kNm}$ based on an incorrect assumption of a design span of this beam equalled to $3.0 \mathrm{~m}$. The same author in the project from 2008 significantly altered computational assumptions without performing any research or opencast works. He assumed a static scheme of a three-span continuous beam with a span of $3.0 \mathrm{~m}$, and design loads equal: the weight of layers (after laying stone slabs) $7.20 \mathrm{kN} / \mathrm{m}^{2}$, and the operational load $3.90 \mathrm{kN} / \mathrm{m}^{2}$, on one rib $3.44 \mathrm{kN} / \mathrm{m}$. The bearing capacity was still determined by assuming the thickness of the concrete overlay $h_{f}=9.0 \mathrm{~cm}$, reinforcement on the top and bottom, the surface of the reinforcement was $0.8 \mathrm{~cm}^{2}$, the concrete cover equalled to $4.0 \mathrm{~cm}$ which resulted in the bearing capacity of the beam of $M_{R d}=4.04 \mathrm{kNm}$. It is important to emphasize that the upper reinforcement was found neither during the opencast nor demolition works. During the opencast works an "old" screed was found under the marble floor on the Ackerman floor, which was estimated to be $6.0 \mathrm{~cm}$ thick (the combined thickness of the concrete overlay and the old screed was $9.0 \mathrm{~cm}$ as a result), which was covered with a fibreboard $1.0 \mathrm{~cm}$ thick. Comparing it with the construction project from 2007 it was stated as two even layers of $2.5 \mathrm{~cm}$. The new floor layers were made of a $6.5 \mathrm{~cm}$ concrete screed and a $2.0 \mathrm{~cm}$ stone slab on a $1.0 \mathrm{~cm}$ layer of adhesive.

Basing on the floor opencast works, the computational value of the own weight load equalled to $8.67 \mathrm{kN} / \mathrm{m}^{2}$ was determined in relation to the significantly lower $\left(1.47 \mathrm{kN} / \mathrm{m}^{2}\right.$ difference $)$ value equalled to $7.20 \mathrm{kN} / \mathrm{m}^{2}$ that was incorrectly estimated by the designer. The process of reparation work carried on the floor was being monitored to make sure it was performed according to the project recommendations. The assumptions that were made during the expert evaluation of the discrepancies of the actual layout of the floor compared to the design documentation were confirmed as shown in Figure 3. 


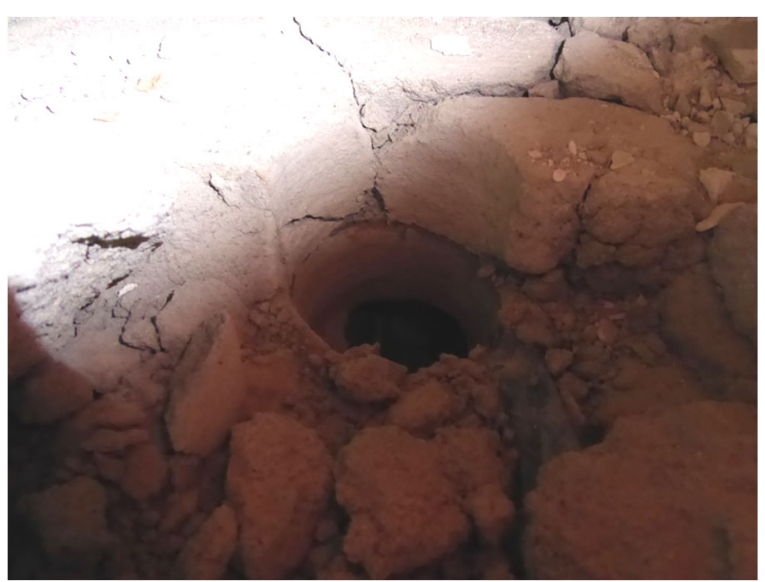

Figure 3. View of floor layers during demolition works

It needs to be noted that the overload of the ceiling layers was caused by the replacement of floor layers that resulted from the solution in the project from 2007 (Studio AZR, 2007). The deployment of layers of increased weight significantly exhausted the operational load of the floor. It should be emphasized that the author of the expert opinion (Studio AZR, 1998) and the project (Studio AZR, 2007) approved of the replacement of the floor layers by an entry to the construction log but a building contractor executed it differently to the instructions that were given by the project. The performance faults that fundamentally resulted from inappropriate completion of the layers under stone slab floor were elaborated in the report (NOT, 2015). It was recommended to replace the damaged stone slabs and repair the existing ones as well as add dilatation. Own calculations of the Ackerman floor bearing capacity were made, geometrical data of the floor cross section were assumed as in Figure 4.

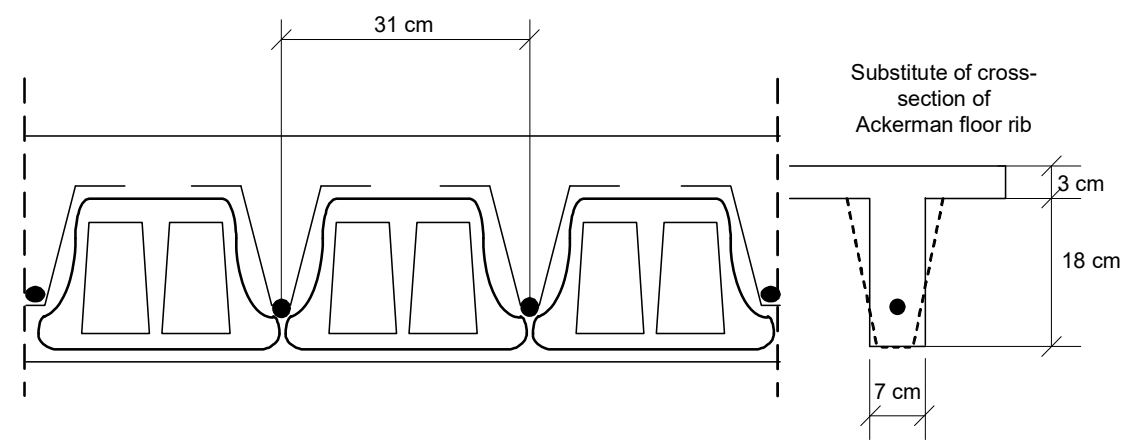

Figure 4. Adoption of cross-section of Ackerman floor rib

Based on the adopted parameters of strength of concrete and steel materials, the effective height of the compressed concrete zone $x_{\text {eff }}$ was determined:

$$
x_{\text {eff }}=A_{s 1} \cdot f_{y d} / b_{d} \cdot f_{c d}=0.61 \mathrm{~cm}
$$

where: $f_{y d}$ - the designed yield strength of steel: $190 \mathrm{MPa}, f_{c d}-$ concrete design compressive strength: $8.0 \mathrm{MPa} ; b_{d}-$ width of beam, $A_{s 1}$ - cross-section of Ackerman floor rib.

The height of the compression zone is smaller than the thickness of the slab $h_{0}=3.0 \mathrm{~cm}$, therefore the crosssection was apparently T-shaped

The load-bearing capacity of the cross-section $M_{R d}$ is equal:

$$
M_{R d}=f_{c d} \cdot S_{c c, e f f},
$$

where $S_{c c, e f f}$ - static moment of Ackerman floor rib,

$$
S_{c c, e f f}=A_{c c, e f f} \cdot\left(h_{0}-\frac{x_{e f f}}{2}\right)=34.47 \mathrm{~cm}^{3},
$$

resulting in: $M_{R d}=2.77 \mathrm{kNm}$.

The load on the floor slab with individual floor layers was established based on the opencast works that had been made. Two parameters were calculated based on the data from the obtained results: characteristic loads of $7.16 \mathrm{kN} / \mathrm{m}^{2}$ 
and design loads of $8.67 \mathrm{kN} / \mathrm{m}^{2}$. Assuming a continuous beam scheme, the value of maximum moment $M_{c w}$ from the calculated deadweight load per beam width $b_{d}=31 \mathrm{~cm}$ was determined: $M_{c w}=2.42 \mathrm{kNm}$. Hence, the load capacity for the operational load was $0.34 \mathrm{kNm}$ per ceiling rib.

The value of design operational loads was $1.22 \mathrm{kN} / \mathrm{m}^{2}-$ the design assumed $3.90 \mathrm{kN} / \mathrm{m}^{2}$.

The next step was to check the load-bearing capacity $M_{c w}$ proj of the floor taking into consideration the load assumed in the design, i.e. with the designed floor layout (Studio AZR, 2007), meaning the operational load of the floor layers (in this case the floor slabs $2 \mathrm{~cm}$ thick) would amount to $6.90 \mathrm{kN} / \mathrm{m}^{2}$, that is $M_{c w}$ proj $=1.93 \mathrm{kNm}$. Therefore, the load capacity for operational loads would be $0.84 \mathrm{kNm}$ per ceiling rib. The maximum value of the calculated operational loads would amount to $2.99 \mathrm{kN} / \mathrm{m}^{2}$ which would be less than the value assumed in the design documents, however the concert hall could be used only as an office space.

Further step was to estimate the deflection under characteristic loads. The moment of inertia of the cross-section of the reinforced concrete Ackerman floor was calculated based on the relationship:

$$
I=\frac{b_{d} \cdot x_{e f f}^{3}}{3}+\alpha \cdot A_{s 1}\left(h_{0}-x_{e f f}\right)=1914 \mathrm{~cm}^{4}
$$

where $\alpha=E / E_{c m}, E_{c m}$ - Young's modulus of concrete.

The floor deflection (simplified method) was calculated from the dependence:

$$
f=\frac{5 M_{R d} l_{0}^{2}}{48 E_{c m} I}=0.32 \mathrm{~cm} .
$$

Limit value of floor deflection: $f_{\text {dop }}=l_{0} / 300=300 \mathrm{~cm} / 300=1.0 \mathrm{~cm}-$ the condition of usability was fulfilled.

The design engineer changed the premises of his calculations again after he received the expert opinion written by the authors of this paper in order to prove that the floor load-bearing capacity is sufficient. To validate his opinion, he used both incorrect the thickness of the concrete overlay and the effective span range. Additionally, in his document, he put forward a different thickness of the floor layers collected in the opencast works that suggests a different weight of floor construction.

\section{Discussion and proposal of repair works}

The solutions that were presented in the report (Central Technical Organization, 2015) consisted of replacing the damaged stone slabs with the new ones and stitching cracks on the floor. It was an incorrect solution due to the overload of the floor. The aforementioned overload was the result of both the faulty performance of the renovation work that was non-confirmative with reference to the design recommendations (Studio AZR, 2007) as well as the design errors. Based on technical state of the floor and statistic strength calculations, four different technical solutions for floor layers on Ackerman ceiling (including changing the stone-slab floor layer) were recommended. The first solution was to remove stone-slab floor layers down to the fibreboard and to replace it with a light wooden floor. The removal of the top layers would significantly reduce the dead weight of the floor layers to the calculated value of $5.79 \mathrm{kN} / \mathrm{m}^{2} \mathrm{which}$ would ensure an acceptable level of design load for the new wooden flooring and operational load at the level of $4.10 \mathrm{kN} / \mathrm{m}^{2}$. The second proposed solutions was the removal of all the floor layers down to the concrete overlay of the Ackerman ceiling. The mentioned removal would reduce their deadweight load to $3.92 \mathrm{kN} / \mathrm{m}^{2}$. The margin of the permissible design load for the new top layer of the floor and the floor operational load would come to $5.97 \mathrm{kN} / \mathrm{m}^{2}$. Due to the using of a dry cement mortar and fine sand $4 \mathrm{~cm}$, thick, and relaying new stone slabs, $2 \mathrm{~cm}$ thick, the load capacity for a design operational load would come to $4.39 \mathrm{kN} / \mathrm{m}^{2}$. The third proposed solution was the demolition of the top layers of the floor as described in the second solution. That would enable making the floor in the form of a wooden surface on a double cross joist. In case of this solution after using/applying a levelling screed with thickness of $4 \mathrm{~cm}$ and laying a $22 \mathrm{~mm}$ wooden parquet there would be enough capacity left to estimate the operational load at the level of $4.88 \mathrm{kN} / \mathrm{m}^{2}$. The fourth solution is hypothetical only and it was prepared on a specific request of the user of the building. It involves reinforcing the supporting structure of the Ackerman floor in order to shift the designed operational loads - weight of the crowd attending concerts. Such reinforcement could be achieved by using a steel supporting construction based on the existing structural pillars. It could also be accomplished by reinforcing the floor using modern reinforcing materials in the form of a carbon fiber tape (or glass or aramid fiber tapes). Nevertheless, even if the floor was reinforced, it would still require demolition of the existing stone-slab floor as well as adhesive and concrete floor layers, before reconstructing the floor according to the project on the stabilised sand. All four solutions for the new layer arrangement on the Ackerman floor involved the replacement of the stone-slab floor. The third solution, which offered possibly the biggest relief to the floor construction, was recommended for implementation. Based on the control computations and evaluation of the technical condition, it was recommended to put the concert hall out of use until the renovation work was completed. The appearance of the designed operational loads imposed on the possible weight of a crowd attending a concert and a dead weight of the existing floor construction could create a 
risk of construction disaster. It was recommended to carry a continuous technical supervision while the floor was being renovated. The results of the mentioned supervision has confirmed the conclusions from the expert findings regarding the incompatibility of the arrangement of the layers with the design documentation and the thickness of the concrete overlay.

\section{Conclusions}

Implementation of renovation works of historic building, constituting the cultural heritage of the country, is an extremely complicated task. It is so complicated due to legal regulations concerning the protection of monuments and technical issues surrounding interference in civil structure of an object. Special attention needs to be paid to the parameters of building materials, construction characteristics and possible impacts that may occur (Chmielewski \& Kruszka, 2015). The calculations that were carried out in order to check the stability and usability states of the Ackerman floor of the concert hall and the assessment of the floor construction show that:

- the completion of additional floor layers (by the contractor) and incorrect determination of the concrete overlay thickness of the Ackerman floor (done by the designer) have the overload of the load-bearing structure of the Ackerman floor - breach of permissible operational loads foreseen not only for concert halls but also for office accommodations,

- it was recommended to exclude the concert hall from use until the renovation works of floor layers (or reinforcement of the ceiling) were completed. The construction supervision office was also informed about the discoveries of the report as recommended by the Polish Construction Law (2013).

When planning a renovation of a historical building it is usually required to take into account the actual technical state of a construction and parameters of the pre-existing built-in materials (Kruszka, 2018; Chmielewski \& Kruszka, 2015; Chmielewski et al., 2016; Chmielewski, 2018). It is unacceptable to apply solutions that change the characteristic of the behavior of construction. It is a good practice to choose solution to ensure the construction complies with the requirements of the permissible compressive stress, especially if it would cause tensile or additional shear.

The user of the concert hall had decided to choose the option that lightens the roof structure by the removal of all the floor layers in the mentioned room. The construction works were carried out with the use of light manual equipment due to the possibility of damage to the construction of the Ackerman floor. The construction works were carried out in accordance with construction standards and ensured the safety of the structural components of the building. Currently, the concert hall is used in accordance with its intended purpose (without any restrictions).

\section{References}

Brühwiler, E., \& Denarié, E. (2013). Rehabilitation and strengthening of concrete structures using ultra-high performance fibre reinforced concrete. Structural Engineering International, 23(4), 450-457. https://doi.org/10.2749/101686613X13627347100437

Central Technical Organization. (2015). Technical report on the reasons for damages to a marble floor in the concert hall (Unpublished report). NOT, Warsaw (in Polish).

Chmielewski, R. (2018). Analysis of retaining wall stability in areas specified in register of objects of cultural heritage. $M A T E C$ Web of Conferences, 174, 03013. https://doi.org/10.1051/matecconf/201817403010

Chmielewski, R., \& Kruszka, L. (2005-2017). Expertises and technical opinions in the area of building structures (Unpublished reports). WAT, Warsaw (in Polish).

Chmielewski, R., \& Kruszka, L. (2015). Application of selected modern technology systems to strengthen the damaged masonry dome of historical St. Anna's Church in Wilanów (Poland). Case Studies in Construction Materials, 3, $92-101$. https://doi.org/10.1016/j.cscm.2015.08.001

Chmielewski, R., Kruszka, L., \& Lalka, J. (2016). Aspekty przebudowy zabytkowych budynków murowanych o bezwieńcowej konstrukcji stropów międzykondygnacyjnych. Biuletyn WAT, 684(4), 123-141. https://doi.org/10.5604/12345865.1228959

Kruszka, L. (2018). Reinforcement of brick historic buildings threatened by structural damages or by failure. MATEC Web of Conferences, 174, No 03013. https://doi.org/10.1051/matecconf/201817403013

Kumar, M. (2016). Structural rehabilitation, retrofitting and strengthening of reinforced concrete structures. International Journal of Structural and Construction Engineering, 10(1), 37-41.

Polish Construction Law. (2013). Journal of Laws of 2001, item 1409 (in Polish)

Radziszewska-Zielina, E., Kania, E., \& Śladowski, G. (2018). Problems of the selection of construction technology for structures in the centres of urban agglomerations. Archives of Civil Engineering, 64(1), 55-71. https://doi.org/10.2478/ace-2018-0004

Studio AZR. (2007). Construction design-executive. Volume II-construction, superstructure and completion of the renovation of the New Dziekanka outbuilding and extension of the elevators to the terrace. Warsaw (in Polish).

Studio AZR (1998). Technical report on the outbuilding of the New Dziekanka in the building complex of D. S. Dziekanka. Warsaw (in Polish). 